\title{
Hematological, Biochemical and Blood Lead Level Profile among Gasoline Exposed Station Workers in Sulaimaniya City
}

\author{
Sirwan M. Mohammed \\ Department of Biology, School of Science, University of Sulaimaniya, Kurdistan Region - F.R. Iraq
}

\begin{abstract}
Occupational exposure to toxic fumes of leaded gasoline has become a major public health concern. These fumes contain tremendous life threatening toxins, which can cause abnormal alterations in the functioning of many vital organs. The current study intended to find out any changes in the hematological and biochemical profile in correlation to the Blood lead levels among individuals occupationally exposed to gasoline and gasoline vapors as a fist line risk group. The mean Blood lead level among gasoline station workers $(6.2 \pm 5 \mu \mathrm{g} / \mathrm{dL})$, was significantly higher $(P=0.017)$ than controls $(2.1 \pm 6.4 \mu \mathrm{g} / \mathrm{dL})$, and there was a significant $(P=0.003)$ increase in Blood lead level $(10.6 \pm 3.9 \mu \mathrm{g} / \mathrm{dL})$ of smoking workers compared to nonsmoking workers. The latter is above the permitted value for adult individuals. The workers had higher $(P=0.01)$ concentration of hemoglobin $(15.9 \mathrm{gm} / \mathrm{dL})$, whereas, other hematological counts were within the normal limits. Serum alkaline phosphatase and uric acid were significantly higher among the workers $(338 \pm 49.5$ and $6.1 \pm 1.7)$ with $P$-value of (0.0001 and 0.038 respectively), whereas, no statistically significant differences were found among serum alanine transaminase, aspartate transaminase, creatinine, cholesterol and albumin.
\end{abstract}

Index Terms-Occupational exposure, leaded gasoline, hematological \& Biochemical findings, gasoline station workers.

\section{INTRODUCTION}

Lead $(\mathrm{Pb})$ is one of the oldest chemical toxins and a harmful environmental pollutant. It is found almost everywhere (Nordic Council, 2003; Karrari, Mehrpour and Abdollahi, 2012). Although, Lead is one of the most useful industrial elements, but serves no useful function in the human body (Mahmoud, 1997). In fact, it is not degradable in nature and will thus, once released to the environment, stay in circulation. While naturally occurring, it can be released to the

ARO-The Scientific Journal of Koya University

Volume II, No (1)2014, Article ID: ARO.10036, 6 pages

DOI: $10.14500 /$ aro.10036

Received 26 November 2013; Accepted 17 March 2014

Regular research paper: Published 15 April 2014

Corresponding author's e-mail: sirwan.mostafa@gmail.com

Copyright (C) 2014 Sirwan M. Mohammed. This is an open access article distributed under the Creative Commons Attribution License. environment as a result of many industrial processes such as production of batteries, paints, varnishes and as antidetonation agent in gasoline (U.S. Dep. of Health and Human Services, 2007; Cabaravdic, et al., 2010). Gasoline is the common term for petroleum fuel used mainly for internal combustion engine it is complex, volatile and contains more than 500 saturated or unsaturated hydrocarbons having from 3 to 12 carbon atoms. The Majority of its noxious risk comes from breathing exhaust fumes, evaporative and refueling emissions rather than from irregular skin contact from spills (Amal, 2009) Although, leaded gasoline is phased-out in many significant regions of the world such as, USA and Europe, lead is still used as an additive to benzene to help reduce engine knocking and boost octane ratings in many developing countries, including Iraq and Kurdistan region. Occupational exposure has become one of the characteristics of the modern life, nowadays human being are exposed to many types of environmental pollutants at different stages of their life span and at different levels. Unfortunately, the majority of them are harmful. One of the oldest harmful agents known to mankind is lead. Unfortunately, day by day the amount of air emissions of lead and other harmful exhausts from vehicles are now increasing in an unacceptable manner in Iraq and Kurdistan, because of an increased motorization and urbanization, which ultimately, leads to excessive emission of more and more noxious gases and other unsafe fumes. Despite all of these hazards, yet, we lack a clear and strict regulation to maintain a healthy occupational and general public environment.

In Sulaimaniya city, leaded gasoline station workers are occupationally exposed to many hazardous and noxious fumes on a daily basis during their work hours at the filling stations. They almost lack the protective measures at work place, because of either their carelessness or the equipments are not provided, or as a result of the lack of education about the health issues of daily leaded gasoline and benzene exposure. In order to give awareness about some one's recent exposure to this metal, blood lead level (BLL) provides the best parameter (Lynda, et al., 2011). According to the Centers for Disease Control and Prevention (CDC), an elevated BLL is defined as $\geq 10 \mu \mathrm{g} / \mathrm{dL}$. While In children, BLLs must not exceed $5 \mu \mathrm{g} / \mathrm{dL}$. An increase in BLL $\geq 10 \mu \mathrm{g} / \mathrm{dL}$ or even lower, have been associated with developmental delays, deficits in behavioral functioning, decreased stature, and diminished hearing acuity and difficulty learning (Amal, et al., 
2009; Hamad, 2008). In fact, no safe BLL in children has been identified (CDC, 2013). Exposure to leaded gasoline can be harmful to most body systems, absorbed primarily through respiratory and digestive routes and interfering with cellular function and metabolism. Elevated BLL produce harmful effects on hematopoietic, hepatic, renal, reproductive, and gastrointestinal systems (Hernandez, et al., 2003). Many recent studies concluded that chronic exposure to lead is associated with adverse effects on renal function impairment and increased serum uric acid level in laboratory animals and man (Ali Khan, 2013; Alasia, Emem-Chioma and Wokoma, 2010). There is controversy concerning the direction of change of renal function parameters following chronic lead intoxication. Chronic exposure to high BLL leads to adverse effects on renal function and the hematopoietic system in both animals and humans (Odigie, et al., 2004; Elwood and Gallacher, 1984). Others concluded that Chronic lead exposure causes hypertension, abnormal changes in lipid profile, atherosclerosis and cardiovascular disease, which are associated with, and, in part, due to oxidative stress(Zhenmin, et al., 2004; Lynda, et al., 2011). Concerning the hematological adverse effects many studies concluded a decrease in Hemoglobin content and hematocrit value in parallel manner with decrease in red blood cell count. , an increase in, the WBC count (Abdel Aziz, Al Agha and Shehwan, 2006).

The International Agency for Research on Cancer (IARC) has determined that inorganic lead is probably carcinogenic to human (U.S. Dept. of Health and Human Services, 2007). According to The World Health Organization (WHO), Human exposure to gasoline has been associated with a range of acute and long-term adverse health effects and diseases, including cancer and aplastic anemia. Chromosomal aberrations and sperm abnormalities. (WHO, 2010). On the other hand, benzene in the regular fuel, which is a widespread environmental chemical associated with increased risk of hematological malignancies, particularly with acute myeloid leukemia (U.S. EPA, 2009; Carugno, et al., 2012). Based on the above literature about the health risks of leaded gasoline exposure, the current study intended to find out any changes in the hematological and biochemical profile in correlation to the BLL among persons occupationally exposed to gasoline and gasoline vapors as a fist line risk group.

\section{MATERIALS AND METHODS}

The present study was conducted from January 2013 through July 2013, and intended to recognize the risk factors associated with leaded gasoline exposure and to determine biochemical and hematological profile among gasoline station workers in Sulaimaniya city. The methodology used in this study involved questionaries' data gathering, as well as, collection, preparation, and storage of the blood samples. It also included the different laboratory tests that were used to investigate biochemical, hematological and BLL profile among occupationally exposed gasoline station workers. The participants were given a prior insight about the aim of the study and the contribution was elective. Also, each of them received a copy of their results with some interpretation. The study sample included 34 randomly selected filling-pump workers at ten gasoline stations located in Sulaimaniya city. Having mean age of $(32 \pm 11)$ years with average serving of $(4 \pm 4.7)$ years in gasoline stations and average daily work of about 7 hours. The questionnaire for each subject was filled included, age, duration of work, safety measures, smoking habits and self-reported complains. Conversely, sixteen individuals with average age of $(34 \pm 9)$ years from general population of Sulaimaniya residents who almost have no history of being worked at gas stations and matching the experimental group in age and sex were enrolled as a control group. Complete blood counts were obtained from the whole blood specimens at the same day of collection, using automated hematology analyzer from SWELAB, Sweden.

Serum Alanine Transaminase (ALT), Aspartate Transaminase (AST), alkaline phosphatase (ALP), creatinine, albumin and uric acid were analyzed in Medya clinical laboratory by using KENZA 240 TX/ISE chemical auto analyzer, BioLabo, France. While the BLL were obtained by diluting one milliliter of serum in 9 milliliter of deionized water, later the value of each sample were obtained by using Inductively Coupled Plasma-Optical Emission Spectrometry, OPTIMA 2100DV from Perkin Elmer. The statistical analysis used was included independent-test to compare means. The data were analyzed by using the Statgraphics Plus Version 4.0. The P-values less than 0.05 were considered significant.

\section{RESULTS}

\section{A. Blood Lead Level}

Out of the 12 stations, the workers at 10 stations accepted to give blood samples for BLL, biochemical and hematological analysis. In general, the protective measures in the stations were very low or sometimes absent. This, in turn, may contribute in development of health complaining of some workers. The most frequently self-reported health complaints were respiratory issues; especially dyspnea, fatigue, cough, irritability, red eyes and head ache. It is worthy to be mentioned that the majority of these complaints were appeared after the period of working at gasoline stations. The results of the present study revealed, a statistically significant increase $(P-$ value $=0.017)$ in the mean BLL value among gasoline station workers $(6.2 \pm 5 \mu \mathrm{g} / d L)$, when compared to mean BLL of control group $(2.1 \pm 6.4 \mu g / d L)$, as shown in Fig. 1 .

Among the studied sample of workers, the smoking individuals $(n=7)$ had higher $(P=0.003)$ mean of BLL $(10.6 \pm 3.9 \mu \mathrm{g} / \mathrm{dL})$, as well as, the symptoms were more intensive among them when compared to non-smoking workers $(4.8 \pm 5.7 \mu g / d L)$. See Fig. 2 .

The BLL distribution among both studied groups are presented in Table I. A remarkable percentage of the workers had their BLL located within the higher ranges. Forty one percent of workers had BLL in between 1-5 $\mu \mathrm{g} / \mathrm{dL}$, while only $6 \%$ of controls having the same BLL range. The BLL range of $5-10 \mu \mathrm{g} / \mathrm{dL}$ was presented in $26 \%$ and $6 \%$ of workers and controls successively. As well as, $26 \%$ of workers had BLL located between $10-20 \mu \mathrm{g} / \mathrm{dL}$ versus $12 \%$ of controls.

Labor duration and exposure of gasoline station workers in relation to their BLL values are represented in Fig. 3. As an 
average, the workers were served for $(4 \pm 4.7)$ years in gasoline stations along with average daily work of about (7) hours. As a percentage fraction, $40 \%$ of workers served for more than 5 years.

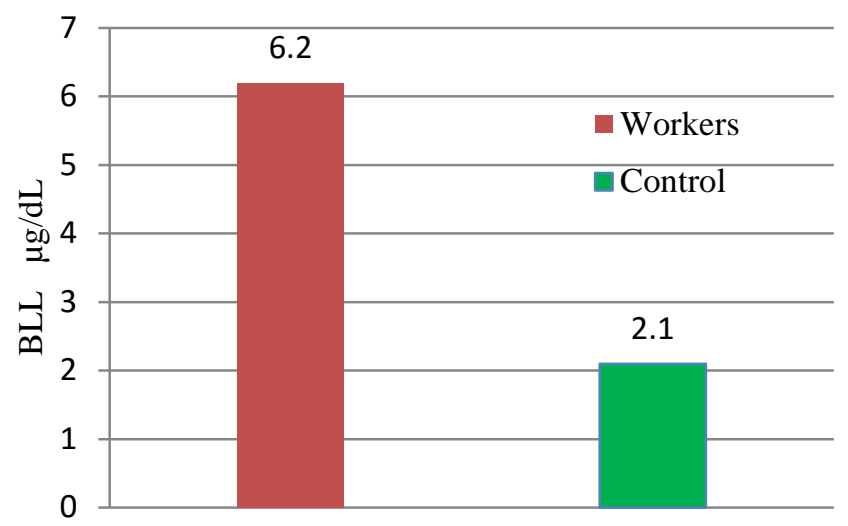

Fig. 1. Mean BLL values between workers and control group

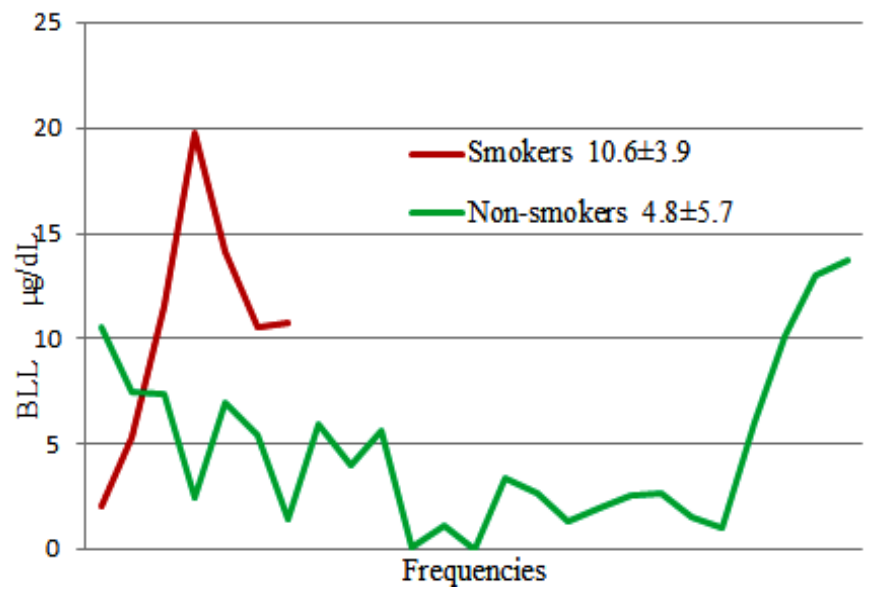

Fig. 2. Comparison of BLL between smoking and non-smoking workers

TABLE I

DISTRIBUTION OF BLL VALUES OF BOTH STUDIED GROUPS

BLL $\mu \mathrm{g} / \mathrm{dL} \quad$ Control n $(\%) \quad$ Workers n (\%)

\begin{tabular}{ccc}
\hline$<1$ & $12(75)$ & $2(5.88)$ \\
$1-5$ & $1(6.25)$ & $14(41.2)$ \\
$5-10$ & $1(6.25)$ & $9(26.5)$ \\
$10-20$ & $2(12.5)$ & $9(26.5)$ \\
\hline \hline
\end{tabular}

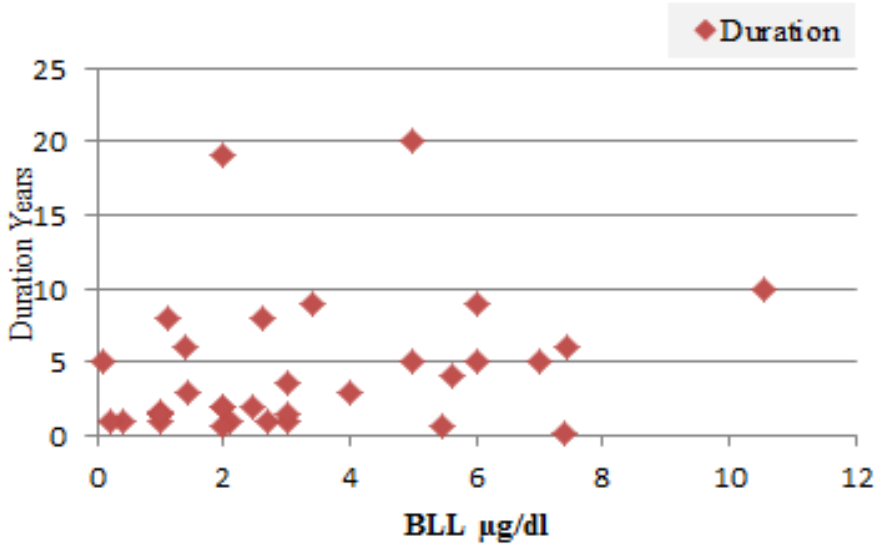

Fig. 3. Blood lead levels of workers in relation to their work period $(n=34)$.

\section{B. Hematological profile}

Anti-coagulated fresh blood samples were analyzed at the same day of collection for obtaining complete blood count; the data are presented in Table II.

TABLE II

MEAN VALUES OF HEMATOLOGICAL PARAMETERS OF BOTH STUDIED GROUPS

\begin{tabular}{|c|c|c|c|c|c|}
\hline Subjects & Parameter & Mean & SD* & $\begin{array}{c}\text { P- } \\
\text { Value }\end{array}$ & $\begin{array}{l}\text { Level } \\
\text { of Sig. }\end{array}$ \\
\hline \multirow{7}{*}{ 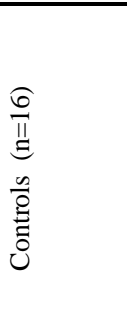 } & $\mathrm{Hgb}$ & 15.1 & 19 & & \\
\hline & $\mathrm{RBC}$ & 5.2 & 0.29 & & \\
\hline & HCT & 44.8 & 2.6 & & \\
\hline & $\mathrm{MCH}$ & 28.7 & 1.3 & & \\
\hline & $\mathrm{MCHC}$ & 34.1 & 1.27 & & \\
\hline & TWBC & 8066 & 1769 & & \\
\hline & PLT & 199 & 36.1 & & \\
\hline \multirow{7}{*}{ 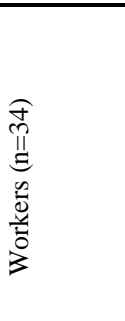 } & $\mathrm{Hgb}$ & 15.9 & 1.02 & 0.01 & $* *$ \\
\hline & $\mathrm{RBC}$ & 5.4 & 0.38 & 0.09 & Non \\
\hline & HCT & 44.2 & 3.3 & 0.39 & Non \\
\hline & $\mathrm{MCH}$ & 29.7 & 2.4 & 0.61 & Non \\
\hline & $\mathrm{MCHC}$ & 36.1 & 1.07 & 0.42 & Non \\
\hline & TWBC & 7400 & 1649 & 0.15 & Non \\
\hline & PLT & 212 & 36.4 & 0.18 & non \\
\hline
\end{tabular}

*standard deviation, ** significant.

The statistical analysis showed significant increases $(P=$ 0.01) in hemoglobin (Hgb) content of the worker's blood in comparison to controls. Oppositely, no significant differences were found between the total red blood cell count (RBC), hematocrit value (HCT), mean corpuscular volume (MCV), mean corpuscular hemoglobin $(\mathrm{MCH})$, mean corpuscular hemoglobin concentration (MCHC), blood platelet count (PLT), mean platelet volume (MPV), total and differential white blood cells (WBC).

\section{Biochemical parameters}

Liver function tests

The activities of some liver enzymes in controls and gasoline station workers are shown in Fig. 4. The mean level of serum 
ALP of the workers $(338 \pm 49.5)$ was significantly higher $(P=0.0001)$, in comparison to the control group (257 \pm 43.6). Whereas, no statistically significant differences $(P=$ 0.46 and $=0.66$ ) were found between the mean levels of the ALT and AST ( $49 \pm 80$ and $33 \pm 23.8$, respectively). As well as, no statistically significant $(P=0.78)$ differences found between the total cholesterol of the workers and control group (195 \pm 29 and $198 \pm 34.9$, respectively).

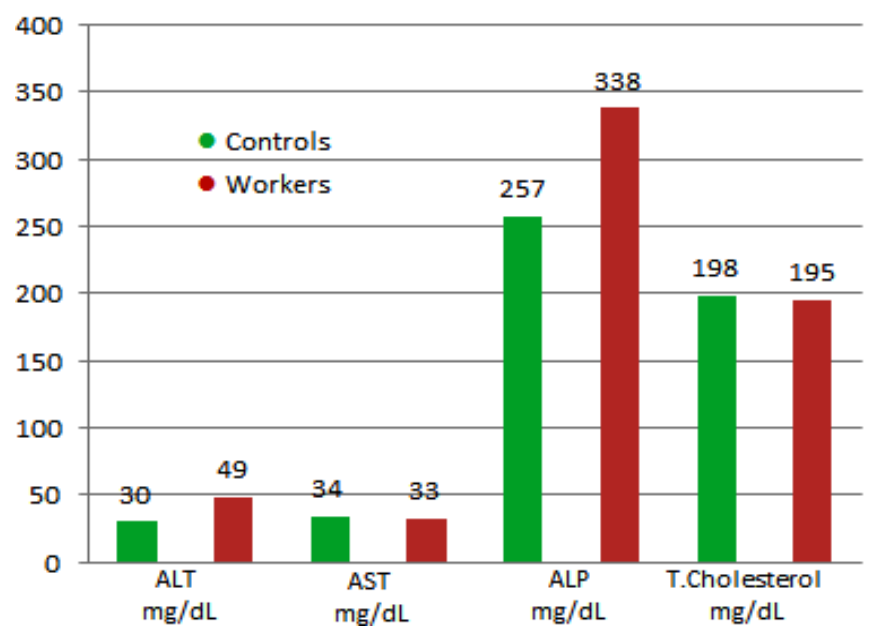

Fig. 4. Mean values of some liver function parameters.

\section{Renal function}

The mean level of serum uric acid in gasoline station workers $(6.1 \pm 1.7)$ was statistically higher $(P=0.038)$, compared to the control group $(4.9 \pm 0.87)$, whereas, no statistically significant differences $(P-$ value $=0.08)$ was found between the mean level of serum creatinine in both workers and control group $(0.7 \pm 0.6$ and $0.8 \pm 0.9$, respectively). As well as, no statistically significant $(P=0.18)$ differences found between the serum albumin of the workers and control group ( $4.8 \pm 36.4$ and $4.5 \pm 36$, respectively) as shown in Fig. 5.

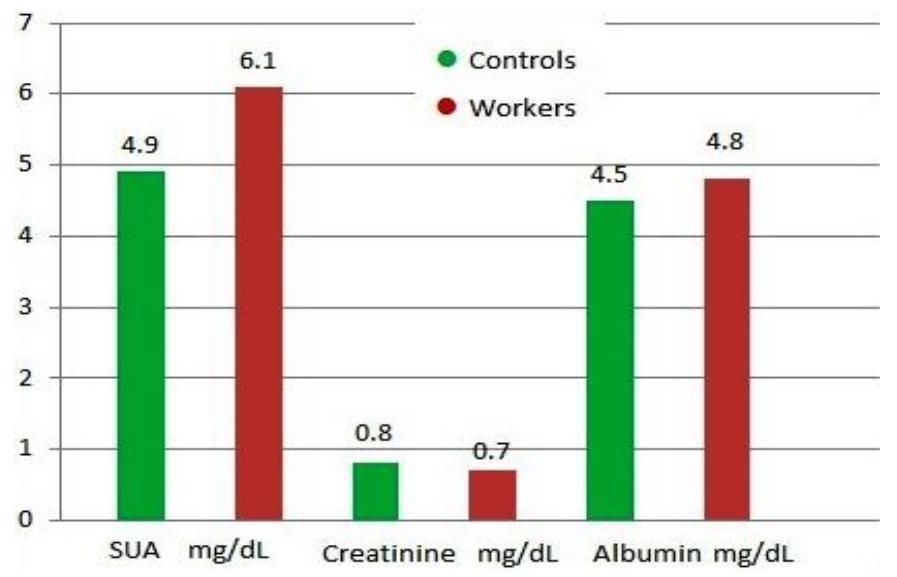

Fig. 5. Mean values of some renal function-related parameters among both studied groups.

\section{DISCUSSION}

Sulaimaniya city experience serious and continuously increasing environmental and occupational problems. Gasoline station workers are regularly exposed to many hazardous toxins and noxious vapors, among the most risky toxins are those of lead and benzene fumes. Which they can cause abnormal alterations in the functioning of many vital organs (Abdel Aziz, Al Agha, and Shehwan, 2006; Ali Khan et al., 2011) and they are associated with increased risk of hematological malignancies, particularly with acute nonlymphocytic (myeloid) leukemia (Baan, 2009).

Unfortunately, the majority of the workers are neglecting or lacking the protective safety measures such as; facemasks, protective cloths, gloves and washing themselves after finishing their working shift. In turn, this carelessness makes them more susceptible to those toxic fumes. The results in the present study indicate that BLL are significantly higher among gasoline stations workers $(6.2 \mu \mathrm{g} / \mathrm{dL})$ when compared to control subjects $(2.1 \mu \mathrm{g} / \mathrm{dL})$. Though, according to CDC these values are within accepted level of BLL. In a similar study done in Basrah-Iraq, Al-Rudainy, (Al-Rudainy, 2010) found an elevated BLL $(14.1 \mu \mathrm{g} / \mathrm{dL})$, among benzene workers, which is higher than the results of current study, this differences may belongs to the geographical variations and toxic exposures of Gulf war weapons. A part of this increase may belong to the regular daily inhalation of leaded benzene fumes and neglecting the protective measures. Nonsurprisingly, among the workers of the present study, the smoking individuals had higher mean of BLL $(10.6 \mu \mathrm{g} / \mathrm{dL})$, which is according to CDC is an elevated level of BLL. As well as, the clinical symptoms were more intensive among them when compared to non-smoking workers. Since the inhalation of benzene and cigarette smokes together may have augmentation effects on the accumulation pathways of lead in the body (Grandjean, Niels and Hanne, 1981).

Regarding the hematological findings, the current study showed an increase in $\mathrm{Hbg}$ concentration among workers when compared with the control subjects, which came in parallel with some other recent finding (Uzma, et al., 2008; Hamad, 2008 and Pesatori, et al., 2009). In contrast, the counts of RBC, HCT, MCH, MCHC, MCV, PLT, MPV, WBC and differential WBC counts, were within the normal ranges and had no significant differences with those of controls. The analysis of biochemical parameters showed a significant increase in the concentration of ALP among the workers. Alkaline phosphatase in healthy adults mainly derives from liver, bones and in lesser amount from intestine, kidneys, leukocytes and placenta. An increase in alkaline phosphatase level is frequently associated with a variety of diseases, such as intrahepatic cholestasis, extra hepatic bile obstruction, and hepatitis (Ali Khan, et al., 2013). The reason might be the regular exposure to benzene, leaded gasoline and other chemical derivatives. While no significant differences found between the levels of transaminases ALT and AST among both studied groups. These two latter enzymes are most frequently measured enzymes which reflect hepatotoxicity (Hamad, 2008; Ali Khan, et al., 2013).

In the present study serum uric acid was significantly higher among the workers. This finding is consistent with other 
findings. Which may be due to degradation of purines and pyrimidines or to an increase of uric acid level by either over production or inability of excretion (Abdel Aziz, Al Agha and Shehwan, 2006), whereas, serum creatinine and albumin were within the normal ranges and had no significant differences with those of controls. Although the overall results of the current study are generally consistent with many of previous studies, it might be much more reliable and intensive if we evaded some limitations in the method we applied such as the sample size, cost, multi-source gasoline and other interfering factors for example, allocation of different sources of lead exposure other than gasoline stations alone.

\section{CONCLUSION}

Blood lead levels are slightly elevated among gasoline station workers in Sulaimaniya city and the smoking workers had higher BLL. As well as, the workers had higher hemoglobin concentration. While other hematological parameters were within the normal ranges. The concentrations of serum ALP and SUA were significantly higher among the workers. Whereas, normal levels of the serum creatinine, albumin, total cholesterol, ALT and AST enzymes were found among them. A clear educational and protection policy is required for those who are occupationally exposed to benzene and other noxious gasoline vapors.

\section{ACKNOWLEDGEMENT}

I would like to thank all persons who participated in this study as well as Medya clinical laboratory and Mr. Dler M. Salih, for their enormous cooperation.

\section{REFERENCES}

Abdel Aziz, I.I., Al Agha, S.Z. and Shehwan, O.A., 2006. Hematological and Biochemical Studies for Gasoline Toxicity among Gasoline Workers in Gaza Strip. Al-Aqsa Univ. J., (10), pp.41-55.

Alasia, D.D., Emem-Chioma, P.C. and Wokoma, F.S., 2010. Association of Lead Exposure, Serum Uric Acid and Parameters of Renal Function in Nigerian Lead- Exposed Workers. Int. J. Occup. Environ. Med., 1(4), pp.182190.

Ali Khan, A., Sultan, R., Zamani, GY. and Rahman, S.U., 2013. Biochemical and Hematological Analysis after Exposure to Hazardous Materials during Shoe Making. Journal of Biology and Life Science, 4(2), pp.116-28.

Al-Rudainy, L.A., 2010. Blood Lead Level among Fuel Station Workers. Oman Medical Journal, 25(3), pp.208-211.

Amal, K., 2009. Impact of gasoline inhalation on some neurobehavioral characteristics of male rats. BMC Physiology, (9)21, doi:10.1186/1472-67939-21

Amal, M., Akhlaque, H., Manirul, I. and Bashar, S.A., 2009. Lead Poisoning: An Alarming Public Health Problem in Bangladesh. Int. J. Environ. Res. Public Health, 6(1), pp.84-95.

Baan, R., Grosse, Y., Straif, K., Secretan, B., El-Ghissassi, F., Bouvard, V., et al., 2009. A review of human carcinogens-Part F: chemical agents and related occupations. Lancet Oncol., 10(12), pp.1143-1144.

Cabaravdic, M., Mirjana, M., Jasna, K., and Amra. 2010. Occupational Exposure of Workers at Gas Station to Inorganic Lead. MED ARH, 64(2), pp.107-109.
Carugno, M., Pesatori, AC., Dioni, L., Hoxha, M., Bollati, V., Albetti, B., Byun, HM., Bonzini, M., Fustinoni, S., Cocco, P., Satta, G., Zucca, M., Merlo, DF., Cipolla, M., Bertazzi, PA. and Baccarelli, A., 2012. Increased mitochondrial DNA copy number in occupations associated with low-dose benzene exposure. Environmental Health Perspectives. 120(2), pp.210-215.

Centers of Disease Control and Protection (CDC), 2013. Blood Lead Levels in Children Aged 1-5 Years-United States, 1999-2010. MMWR, (62), pp.245248.

Department of Health and Human Services, 2007. Toxicological Profile for Lead. [pdf] U.S.: Agency for Toxic Substances and Disease Registry. Available at 〈http://www.atsdr.cdc.gov/toxprofiles/tp13.pdf> [Accessed 1 November 2013].

Elwood, P.C. and Gallacher, J.E., 1984. Lead in petrol and levels of lead in blood: scientific evidence and social policy. Journal of Epidemiology and Community Health. 38(4), pp.315-318.

Grandjean, P., Niels, B.P. and Hanne, H., 1981. Influence of smoking and alcohol on blood lead levels. Int. Arch Occup Environ health. 48(4), pp.391397.

Hamad, A.R., 2008. Some Biochemical and Hematological Alterations Associated with Lead Exposure in Gasoline Station Workers in Gaza Strip. M.Sc.thesis, the Islamic University-Gaza, Faculty of Science., pp.37-58.

Hernández-Serrato, M.I., Mendoza-Alvarado, L.R., Rojas-Martínez, R., González-Garza, C., Hulme, J.M. and Olaiz-Fernández, G., 2003. Factors associated with lead exposure in Oaxaca, Mexico. Journal of Exposure Analysis and Environmental Epidemiology. 13(5), pp.341-347.

Karrari, P., Mehrpour O. and Abdollahi M. A., 2012. Systematic review on status of lead pollution and toxicity in Iran; Guidance for preventive measures. DARU Journal of Pharmaceutical Sciences, 20(1), doi: 10.1186/1560-811520-2.

Lynda, A., Mohamed, H., Abderrezek, T. and Seddik K., 2011. Effect of Long-term Exposure to Low or Moderate Lead Concentrations on Growth, Lipid Profile and Liver Function in Albino Rats. Advances in Biological Research. 5(6), pp. 339-347.

Mahmoud, L.A., 1997. Renal Effects of Environmental and Occupational Lead Exposure. Envinm Healh Perspect., 105(9), pp.928-939.

Ni, Z., Hou, S., Barton, CH. and Vaziri, ND., 2004. Lead exposure raises superoxide and hydrogen peroxide in human endothelial and vascular smooth muscle cells. Kidney International. 66(6), pp.2329-2336.

Nordic Council of Ministers, 2003. Lead Review. Available a 〈http://www.who.int/ifcs/documents/forums/forum5/nmr_lead.pdf> [Accessed 1 November 2013].

Odigie, I.P., Ladipo, C.O., Ettarh, R.R and Zebu, M.C., 2004. Effect of Chronic Exposure to Low Levels of Lead on Renal Function and Renal Ultrastructure in Sd Rats. Nigerian Journal of Physiological Sciences, 19(12), pp.27-32.

Pesatori, A.C., Garte, S., Popov, T., Georgieva, T., Panev, T., Bonzini, M., Consonni, D., Carugno, M., Goldstein, B.D., Taioli, E., Fontana, V., Stagi, E., Bertazzi, P.A. and Merlo, D. F., 2009 . Early effects of low benzene exposure on blood cell counts in Bulgarian petrochemical workers. Medicina Del Lavoro, 100(2), pp.83-90.

Rahman, S.U., 2013. Biochemical and Hematological Analysis after Exposure to Hazardous Materials during Shoe Making. Journal of Biology and Life Science., 4(2), pp.116-28.

U.S. Environmental Protection Agency, 2009. Benzene TEACH Chemical Summary. [pdf] U.S.: EPA, Toxicity and Exposure Assessments for Children's Health.

Available at <http://www.epa.gov/teach/chem_summ/BENZ_summary.pdf> [Accessed 1 November 2013].

Uzma, N., Salar, B.M.K.M., Kumar, B.S., Aziz, N., David, M.A. and Reddy, V.D., 2008. Impact of organicsolvents and environmental pollutants on the physiological function in petrol filling workers. International Journal of Environmental Research and Public Health, 5(3), 139-46. 
WHO, 2010. Exposure to Benzene: A Major Public Health Concern. [pdf] Geneva: WHO, Dept. of Public Health and Environment.
Available at 〈http://www.who.int/ipcs/features/benzene.pdf> [Accessed 1 November 2013]. 